\title{
Antitumor function of microRNA-122 against hepatocellular carcinoma
}

\author{
Kazuhiko Nakao • Hisamitsu Miyaaki • \\ Tatsuki Ichikawa
}

Received: 1 January 2014 / Accepted: 6 January 2014/Published online: 17 February 2014

(C) Springer Japan 2014

\begin{abstract}
MicroRNA-122 (miR-122), a highly abundant and liver-specific miRNA, acts as a tumor suppressor against hepatocellular carcinoma (HCC). Decreased expression of miR-122 in HCC is frequently observed and is associated with poor differentiation, larger tumor size, metastasis and invasion, and poor prognosis. Mutant mice with knockout (KO) of the miR-122 locus developed steatohepatitis due to increased triglyceride (TG) synthesis and decreased TG secretion from hepatocytes, and eventually developed HCC. Exogenic miR-122 introduction into miR-122 KO mice inhibited the development of HCC. Target genes of miR-122, including cyclin G1, a disintegrin and metalloprotease (ADAM)10, serum response factor, insulin-like growth factor-1 receptor, ADAM17, transcription factor CUTL1, the embryonic isoform of pyruvate kinase (Pkm2), Wnt1, pituitary tumor-transforming gene 1 binding factor, Cut-like homeobox 1 , and c-myc, are involved in hepatocarcinogenesis, epithelial mesenchymal transition, and angiogenesis. MiR-122 expression is regulated by liver-enriched transcription factors such as hepatocyte nuclear factor (HNF) $1 \alpha$, HNF3 $\beta$, HNF4 $\alpha$, HNF6, and CCAAT/enhancer-binding protein $(\mathrm{C} / \mathrm{EBP}) \alpha$. A positive feedback loop exists between $\mathrm{C} / \mathrm{EBP} \alpha$ and miR-122 and between HNF6 and miR-122, whereas a negative feedback loop exists between c-myc and miR-122. Since cotreatment of 5-Aza-Cd and histone deacetylase inhibitor restored miR-122 expression in HCC cells, epigenetic modulation of miR-122 expression is involved in the suppression of miR-122 in HCC. Several
\end{abstract}

K. Nakao $(\bowtie) \cdot H$. Miyaaki · T. Ichikawa Department of Gastroenterology and Hepatology, Graduate School of Biomedical Sciences, Nagasaki University, Sakamoto 1-7-1, Nagasaki 852-8501, Japan

e-mail: kazuhiko@nagasaki-u.ac.jp experiments suggest that increasing miR-122 levels in HCC with or without antitumor agents may be a promising strategy for HCC treatment.

Keywords MicroRNA-122 (miR-122) - Hepatocellular carcinoma (HCC) $\cdot$ Steatohepatitis

\section{Introduction}

MicroRNA122 (miR-122) accounts for $70 \%$ of the total liver miRNA population, but it is undetectable in other tissues [1-3]. MiR-122 plays important roles in regulating hepatocyte development, differentiation, lipid metabolism, and stress response [2-5]. With regard to liver diseases, miR-122 stimulates hepatitis $\mathrm{C}$ virus (HCV) replication by direct binding to HCV 5'UTR of HCV RNA [4, 6, 7], whereas miR-122 inhibits replication of hepatitis $B$ virus (HBV) by p53-mediated inhibition of HBV transcription [7, 8]. MiR-122 acts as a tumor suppressor and represses hepatocellular carcinoma (HCC) development by binding to target genes involved in cell proliferation, migration, differentiation, apoptosis and angiogenesis in $\operatorname{HCC}[3,5]$. In this review, we focus on the antitumor activity of miR122 against $\mathrm{HCC}$ and describe miR-122 expression in HCC, hepatocarcinogenesis in miR-122 knockout mice, mechanisms of antitumor function of miR-122, regulation of miR-122 gene expression, and therapeutic application of miR-122 against HCC.

\section{Down-regulation of miR-122 in HCC}

Down-regulation of miR-122 in HCC tissue as compared to adjacent normal tissue has been reported in several studies 
[9-15]. Loss of miR-122 expression in HCC is associated with metastasis and poor prognosis [10, 12-15]. Coulouarn et al. reported that the overall survival of patients with low and high miR-122 expression in HCC was $30.3 \pm 8.0$ and $83.7 \pm 10.3$ months, respectively $(p<0.001)$, and that miR-122 repression was associated with poor differentiation status and large tumor size. They also found that the loss of miR-122 expression in HCC tissue was correlated with high proliferation and low apoptotic index [10]. Down-regulation of miR-122 is also observed in numerous human HCC cell lines, although the levels of miR-122 are variable with more than 1000-fold expression differences among cell lines [10]. Lower expression levels of miR-122 are related to the migration and invasion activity of $\mathrm{HCC}$ cells [11].

Serum levels of miR-122 have been determined in patients with chronic liver disease including HCC [16-18]. The miR-122 levels did not significantly differ between patients with and without $\mathrm{HCC}$, but were positively correlated with liver transaminases and negatively correlated with the Model for End-Stage Liver Disease (MELD) score [18], suggesting that serum miR-122 is a novel biomarker for liver injury but not specifically for HCC.

\section{Hepatocarcinogenesis in miR-122 knockout mice}

To elucidate the relevance of miR-122 depletion and HCC development, mutant mice with germ line knockout (KO) or liver-specific knockout (LKO) of the miR-122 locus were generated in two studies [19, 20], and the pathophysiological changes in these mutant mice were investigated. Both KO and LKO mice develop normally and are viable and indistinguishable from wild-type (WT) mice. Both mice exhibit reduced serum cholesterol and triglyceride (TG) levels and develop hepatic steatosis due to TG accumulation and reduced glycogen storage, as well as inflammation and fibrosis. These histological features are similar to steatohepatitis. Eventually, HCC developed in 10-month-old KO mice and 12-month-old LKO mice. The incidence of HCC exhibited significant sex differences; HCC developed in 17 of 19 (89\%) male KO mice and 6 of $26(23 \%)$ female KO mice [19], and in 13 of $26(50 \%)$ male LKO mice and 2 of 20 (10\%) female LKO mice [20].

In the miR-122 KO liver, the expression of Agpat1, which catalyzes TG biosynthesis [21], was up-regulated, and the expression of Cidec (Fsp27), a lipid droplet-binding protein that promotes TG accumulation in hepatocytes [22], was also elevated. 3'UTRs of both Agpat1 and Cidec mRNA contain miR-122 binding sites [20]. MiR-122 significantly repressed luciferase expression from reporter plasmids containing $3^{\prime}$ UTRs of these genes [20]. In addition, the expression of microsomal TG transfer protein
(MTTP), which plays a crucial role in hepatic very lowdensity lipoprotein (VLDL) assembly and secretion [23], was reduced in both mRNA and protein levels. Hydrodynamic injection of the MTTP gene in miR-122 KO mice resulted in an increase in serum VLDL as well as in normalization of serum levels of cholesterol and TG. Surprisingly, the MTTP-restored liver showed significant reduction of hepatic steatosis, inflammation, and fibrosis, as well as recovery of glycogen storage [19]. These results suggest that TG accumulation in the miR-122 KO liver is caused by an increase of TG synthesis in hepatocytes and a decrease of TG secretion from hepatocytes.

In the setting of chronic liver injury, $\mathrm{Ccl} 2$, a monocytechemotactic protein induced in the injured liver, recruits monocytes and dendritic cells to the sites of inflammation [24]. In the miR-122 KO liver, Ccl2 expression increased, and inflammatory cells including monocytes producing IL6 infiltrated. It was confirmed that miR-122 negatively regulates $\mathrm{Ccl} 2$ expression by binding to the $3^{\prime} \mathrm{UTR}$ of $\mathrm{Ccl} 2$ mRNA. Park et al. [25] demonstrated that enhanced production of the tumor-promoting cytokines IL-6 and TNF- $\alpha$ causes hepatic inflammation and activation of the oncogenic transcription factor STAT3. Taken together, these results suggest that over-production of $\mathrm{Ccl} 2$ and consequential IL-6 over-secretion from inflammatory cells contribute to hepatocarcinogenesis in miR-122 KO mice.

The initial sign of epithelial mesenchymal transition (EMT), including loss of the portal distribution of E-cadherin and gain of vimentin expression was observed in the livers of young miR-122 KO mice, followed by the loss of E-cadherin expression in the tumors of aged mice. Similarly, the expression of oncofetal genes such as $\alpha$-fetoprotein (AFP), insulin-like growth factor-1 (IGF-1), and Src, as well as cancer stem cell marker genes such as Prom1, Thy1, and Epcam, were detected in the livers of young miR-122 KO mice, followed by further increases in the tumors of aged mice. The activation of mitogen-activated protein kinase (MAPK) and phosphatidylinositol-3 kinase (PI3K) signaling pathways was also detected in the livers of young miR-122 $\mathrm{KO}$ mice, followed by strong activation in the tumors of aged mice [19]. These data suggest that tumor-related genes are already activated early in the tumor-free livers of young miR-122 KO mice and attributed to tumor initiation and progression.

\section{Mechanisms of antitumor function of miR-122}

Recently, various target genes of miR-122 have been identified to be involved in hepatocarcinogenesis and EMT. Of these, miR-122 directly down-regulates cyclin G1 expression, and an inverse correlation between miR-122 and cyclin G1 expression exists in HCC tissues [26]. Since 
cyclin G1 negatively regulates p53 protein stability by acting on the B' subunit of phosphatase 2A, miR-122 increases the expression of p53 and its transcriptional activities [27].

A disintegrin and metalloprotease 10 (ADAM10), serum response factor (SRF), and insulin-like growth factor-1 receptor (IGF-1R), which promote tumorigenesis, are validated as targets of miR-122 and are repressed by miR-122. ADAM10, SRF, and IGF-1R are up-regulated in HCC tissue compared with the adjacent normal tissue [12]. Zeng et al. suggest the following regulatory circuitry: miR-122 suppresses IGF-1R expression and attenuates IGF-1R/Akt signaling, which sustains glycogen synthase kinase-3 beta $(\mathrm{GSK}-3 \beta)$ activity and in turn represses cyclin D1 expression and cell proliferation. The activated GSK-3 $\beta$ maintains high levels of miR-122 through activating CCAAT/enhancer-binding protein $(\mathrm{C} / \mathrm{EBP}) \alpha$, a transcription factor of the miR-122 gene, which enforces IGF-1R suppression. Disruption of this regulatory circuitry may result in uncontrolled cell proliferation and hepatocarcinogenesis [13]. ADAM17 is another target of miR-122 and is involved in HCC metastasis. Silencing of ADAM17 resulted in a dramatic reduction of in vitro migration, invasion, in vivo tumorigenesis, and angiogenesis, which is similar to that which occurs with the restoration of miR122 [11].

CUTL1, a transcriptional repressor of genes specifying differentiation during development, is a target of miR-122. The amount of CUTL1 protein gradually disappeared during the progression of liver development, which was inversely correlated with the expression of miR-122 [28]. Zinc finger and BTB domain-containing 20 (ZBTB20) is a repressor of AFP gene transcription in normal liver. ZBTB20 directly binds to a region of the AFP promoter and represses its activity [29]. Recently, it was shown that miR-122 indirectly modulates the expression of ZBTB20 and regulates AFP expression [30]. The miR122-silenced HCC cells exhibit a more invasive phenotype and produce more abundant AFP. In these cells, the expression of Cutlike homeobox 1 (CUX1), which is a target of miR-122 and regulates multiple processes including cell-cycle progression, is up-regulated. CUX1 is a positive regulator of miR214. Since ZBTB20 is a target of miR-214, the elevated expression of miR214 represses ZBTB20 translation, followed by increased expression of AFP [30]. The embryonic isoform of pyruvate kinase $(\mathrm{Pkm} 2)$ is a target of miR-122 and is highly expressed in human embryonic stem cells (hESCs) and HCC cells. During the differentiation process of hESCs into mature hepatocytes, a reciprocal expression pattern is observed between miR-122 and Pkm2. Depleting hESCs and HCC cells of Pkm2, or overexpressing miR122 , leads to a common deficiency in self-renewal and proliferation [31].
Various signaling pathways are deregulated in HCC. The Wnt/ $\beta$-catenin pathway is activated in approximately $30 \%$ of HCCs [32]. Wnt1 is a direct target of miR-122. miR-122 suppresses the expression of Wnt1 protein and subsequently leads to down-regulation of $\beta$-catenin and TCF-4, resulting in the attenuation of the $\mathrm{Wnt} / \beta$-catenin signaling pathway [33]. Pituitary tumor-transforming gene 1 (PTTG1) binding factor (PBF) is a target of miR-122 [34] Overexpression of PBF is observed in $68 \%$ of HCC (13 of 19). PBF increases HCC cell proliferation and invasive ability and promotes tumor growth in nude mice. PBF interacts with PTTG1 and promotes its transcriptional activities by facilitating PTTG1 nuclear translocation, which in turn stimulates the transcription of tumor-promoting genes such as VEGF, FGF-2, c-myc, and MMP-2 [34].

\section{Regulation of miR-122 gene expression}

The expression of miR-122 is correlated with liver-enriched transcription factors (LETFs), such as hepatocyte nuclear factor (HNF) $1 \alpha, \mathrm{HNF} 3 \beta, \mathrm{HNF} 4 \alpha, \mathrm{HNF} 6$, and $\mathrm{C} / \mathrm{EBP} \alpha[10,13,28,35,36]$. These LETFs are coordinately involved in the transcriptional regulation of miR-122 by binding to the miR-122 promoter as transcriptional activators. Hepatocyte differentiation is directed by a positive feedback loop that includes $\mathrm{C} / \mathrm{EBP} \alpha, \mathrm{HNF} 6$, and miR-122 $[13,36]$. As described above, miR-122 indirectly activates $\mathrm{C} / \mathrm{EBP} \alpha$ through IGF-1R suppression and resultant GSK$3 \beta$ activation [13]. MiR-122 stimulates HNF6 expression, although the mechanism is unclear [36].

The expression of miR-122 is suppressed in HCC cells, which is, at least in part, explained by epigenetic modulation of miR-122. The promoter region of miR-122 is

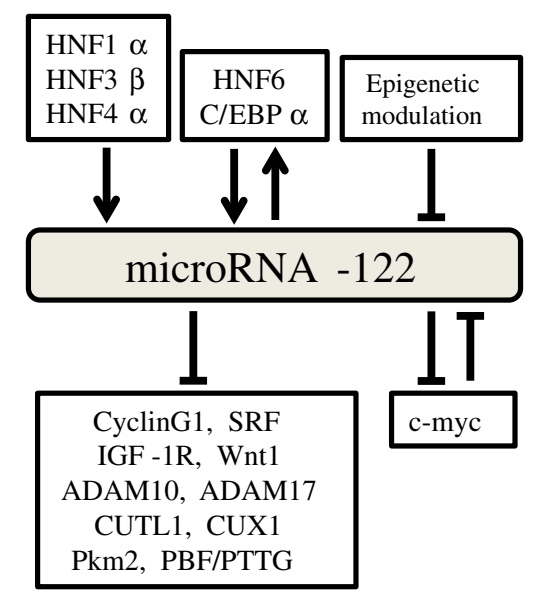

Fig. 1 Regulators of miR-122 expression (upper box), and miR-122 target genes involved in HCC development (lower box) 
hypermethylated in HCC cells, but not in human primary hepatocytes [31]. The treatment of HCC cells with a demethylating agent, 5-Aza- $2^{\prime}$ deoxycytidine (5-Aza-Cd), significantly increases the gene expression of miR-122 [37]. Moreover, in HCC cells, a H3K9 histone methyl transferase down-regulates the gene expression of miR-122 by inhibiting PPAR $\gamma / \mathrm{RXR} \alpha$-mediated promoter activity, which is cancelled by cotreatment with $5-\mathrm{Aza}-\mathrm{Cd}$ and histone deacetylase inhibitor [37].

c-myc can repress miR-122 gene expression by associating with miR-122 promoter and by down-regulating HNF3 $\beta$ expression, whereas miR-122 indirectly inhibits c-myc transcription by targeting the transcriptional activator E2f1 and coactivator Tfdp2 [38].

Figure 1 shows the regulators of miR-122 expression and the downstream target molecules relevant to antitumor activity of miR-122.

\section{Therapeutic application of miR-122 against HCC}

Since miR-122 is a liver-specific tumor suppressor microRNA, increasing miR-122 levels in HCC with or without antitumor agents may be a promising strategy for HCC treatment. In fact, gene transfer of miR-122 into cultured HCC cells induces apoptosis and cell-cycle arrest [39-41]. Hydrodynamic injection of miR-122 into 3-month-old miR-122 KO mice effectively impaired hepatocarcinogenesis and tumor progression, as reflected by a reduction in tumor occurrence and size [19]. Intratumor injection of miR-122 encapsulated in cationic lipid nanoparticles suppressed the growth of HCC xenograft by $50 \%$, which was correlated with repression of target genes and impairment of angiogenesis [42]. In addition, miR-122 sensitizes HCC cells to antitumor agents including doxorubicin [27, 43, 44], vincristine [43], cisplatin [44], and sorafenib [12] by modulating the expression of multidrug resistance genes [43] and the unfolded protein response [44].

Conflict of interest The authors declare that they have no conflict of interest.

\section{References}

1. Girard M, Jacquemin E, Munnich A, Lyonnet S, Henrion-Caude A. miR-122, a paradigm for the role of microRNAs in the liver. J Hepatol. 2008;48:648-56.

2. Lewis AP, Jopling CL. Regulation and biological function of the liver-specific miR-122. Biochem Soc Trans. 2010;38:1553-7.

3. Hu J, Xu Y, Hao J, Wang S, Li C, Meng S. MiR-122 in hepatic function and liver diseases. Protein Cell. 2012;3:364-71.

4. Fukuhara T, Matsuura Y. Role of miR-122 and lipid metabolism in HCV infection. J Gastroenterol. 2013;48:169-76.

5. Szabo G, Bala S. MicroRNAs in liver disease. Nat Rev Gastroenterol Hepatol. 2013;10:542-52.
6. Lanford RE, Hildebrandt-Eriksen ES, Petri A, Persson R, Lindow M, Munk ME, Kauppinen S, Ørum H. Therapeutic silencing of microRNA-122 in primates with chronic hepatitis $\mathrm{C}$ virus infection. Science. 2010;327:198-201.

7. Sendi H. Dual role of miR-122 in molecular pathogenesis of viral hepatitis. Hepat Mon. 2012;12:312-4.

8. Wang S, Qiu L, Yan X, Jin W, Wang Y, Chen L, Wu E, Ye X, Gao GF, Wang F, Chen Y, Duan Z, Meng S. Loss of microRNA 122 expression in patients with hepatitis B enhances hepatitis B virus replication through cyclin $\mathrm{G}(1)$-modulated P53 activity. Hepatology. 2012;55:730-41.

9. Kutay H, Bai S, Datta J, Motiwala T, Pogribny I, Frankel W, Jacob ST, Ghoshal K. Downregulation of miR-122 in the rodent and human hepatocellular carcinomas. $\mathrm{J}$ Cell Biochem. 2006;99:671-8.

10. Coulouarn C, Factor VM, Andersen JB, Durkin ME, Thorgeirsson SS. Loss of miR-122 expression in liver cancer correlates with suppression of the hepatic phenotype and gain of metastatic properties. Oncogene. 2009;28:3526-36.

11. Tsai WC, Hsu PW, Lai TC, Chau GY, Lin CW, Chen CM, Lin CD, Liao YL, Wang JL, Chau YP, Hsu MT, Hsiao M, Huang HD, Tsou AP. MicroRNA-122, a tumor suppressor microRNA that regulates intrahepatic metastasis of hepatocellular carcinoma. Hepatology. 2009;49:1571-82.

12. Bai S, Nasser MW, Wang B, Hsu SH, Datta J, Kutay H, Yadav A, Nuovo G, Kumar P, Ghoshal K. MicroRNA-122 inhibits tumorigenic properties of hepatocellular carcinoma cells and sensitizes these cells to sorafenib. J Biol Chem. 2009;284:32015-27.

13. Zeng C, Wang R, Li D, Lin XJ, Wei QK, Yuan Y, Wang Q, Chen W, Zhuang SM. A novel GSK-3 beta-C/EBP alpha-miR-122insulin-like growth factor 1 receptor regulatory circuitry in human hepatocellular carcinoma. Hepatology. 2010;52:1702-12.

14. Mizuguchi Y, Mishima T, Yokomuro S, Arima Y, Kawahigashi Y, Shigehara K, Kanda T, Yoshida H, Uchida E, Tajiri T, Takizawa $T$. Sequencing and bioinformatics-based analyses of the microRNA transcriptome in hepatitis B-related hepatocellular carcinoma. PLoS ONE. 2011;6:e15304.

15. Karakatsanis A, Papaconstantinou I, Gazouli M, Lyberopoulou A, Polymeneas G, Voros D. Expression of microRNAs, miR-21, miR-31, miR-122, miR-145, miR-146a, miR-200c, miR-221, miR-222, and miR-223 in patients with hepatocellular carcinoma or intrahepatic cholangiocarcinoma and its prognostic significance. Mol Carcinog. 2013;52:297-303.

16. Xu J, Wu C, Che X, Wang L, Yu D, Zhang T, Huang L, Li H, Tan W, Wang C, Lin D. Circulating microRNAs, miR-21, miR-122, and miR-223, in patients with hepatocellular carcinoma or chronic hepatitis. Mol Carcinog. 2011;50:136-42.

17. Qi P, Cheng SQ, Wang H, Li N, Chen YF, Gao CF. Serum microRNAs as biomarkers for hepatocellular carcinoma in Chinese patients with chronic hepatitis B virus infection. PLoS ONE. 2011;6:e28486.

18. Köberle V, Kronenberger B, Pleli T, Trojan J, Imelmann E, Peveling-Oberhag J, Welker MW, Elhendawy M, Zeuzem S, Piiper A, Waidmann O. Serum microRNA-1 and microRNA-122 are prognostic markers in patients with hepatocellular carcinoma. Eur J Cancer. 2013;49:3442-9.

19. Tsai WC, Hsu SD, Hsu CS, Lai TC, Chen SJ, Shen R, Huang Y, Chen HC, Lee CH, Tsai TF, Hsu MT, Wu JC, Huang HD, Shiao MS, Hsiao M, Tsou AP. MicroRNA-122 plays a critical role in liver homeostasis and hepatocarcinogenesis. J Clin Invest. 2012;122:2884-97.

20. Hsu SH, Wang B, Kota J, Yu J, Costinean S, Kutay H, Yu L, Bai S, La Perle K, Chivukula RR, Mao H, Wei M, Clark KR, Mendell JR, Caligiuri MA, Jacob ST, Mendell JT, Ghoshal K. Essential metabolic, anti-inflammatory, and anti-tumorigenic functions of miR-122 in liver. J Clin Invest. 2012;122:2871-83. 
21. Coleman RA, Lee DP. Enzymes of triacylglycerol synthesis and their regulation. Prog Lipid Res. 2004;43:134-76.

22. Matsusue K, Kusakabe T, Noguchi T, Takiguchi S, Suzuki T, Yamano S, Gonzalez FJ. Hepatic steatosis in leptin-deficient mice is promoted by the PPARgamma target gene Fsp27. Cell Metab. 2008;7:302-11.

23. Sundaram M, Yao Z. Recent progress in understanding protein and lipid factors affecting hepatic VLDL assembly and secretion. Nutr Metab (Lond). 2010;7:35.

24. Baeck C, Wehr A, Karlmark KR, Heymann F, Vucur M, Gassler N, Huss S, Klussmann S, Eulberg D, Luedde T, Trautwein C, Tacke F. Pharmacological inhibition of the chemokine CCL2 (MCP-1) diminishes liver macrophage infiltration and steatohepatitis in chronic hepatic injury. Gut. 2012;61:416-26.

25. Park EJ, Lee JH, Yu GY, He G, Ali SR, Holzer RG, Osterreicher $\mathrm{CH}$, Takahashi H, Karin M. Dietary and genetic obesity promote liver inflammation and tumorigenesis by enhancing IL- 6 and TNF expression. Cell. 2010;140:197-208.

26. Gramantieri L, Ferracin M, Fornari F, Veronese A, Sabbioni S, Liu CG, Calin GA, Giovannini C, Ferrazzi E, Grazi GL, Croce CM, Bolondi L, Negrini M. Cyclin G1 is a target of miR-122a, a microRNA frequently down-regulated in human hepatocellular carcinoma. Cancer Res. 2007;67:6092-9.

27. Fornari F, Gramantieri L, Giovannini C, Veronese A, Ferracin M, Sabbioni S, Calin GA, Grazi GL, Croce CM, Tavolari S, Chieco P, Negrini M, Bolondi L. MiR-122/cyclin G1 interaction modulates p53 activity and affects doxorubicin sensitivity of human hepatocarcinoma cells. Cancer Res. 2009;69:5761-7.

28. Xu H, He JH, Xiao ZD, Zhang QQ, Chen YQ, Zhou H, Qu LH. Liver-enriched transcription factors regulate microRNA-122 that targets CUTL1 during liver development. Hepatology. 2010;52:1431-42.

29. Xie Z, Zhang H, Tsai W, Zhang Y, Du Y, Zhong J, Szpirer C, Zhu M, Cao X, Barton MC, Grusby MJ, Zhang WJ. Zinc finger protein $\mathrm{ZBTB} 20$ is a key repressor of alpha-fetoprotein gene transcription in liver. Proc Natl Acad Sci USA. 2008;105:10859-64.

30. Kojima K, Takata A, Vadnais C, Otsuka M, Yoshikawa T, Akanuma M, Kondo Y, Kang YJ, Kishikawa T, Kato N, Xie Z, Zhang WJ, Yoshida H, Omata M, Nepveu A, Koike K. MicroRNA122 is a key regulator of $\alpha$-fetoprotein expression and influences the aggressiveness of hepatocellular carcinoma. Nat Commun. 2011;2:338

31. Jung CJ, Iyengar S, Blahnik KR, Ajuha TP, Jiang JX, Farnham PJ, Zern M. Epigenetic modulation of miR-122 facilitates human embryonic stem cell self-renewal and hepatocellular carcinoma proliferation. PLoS ONE. 2011;6:e27740.

32. Wong CM, Ng IO. Molecular pathogenesis of hepatocellular carcinoma. Liver Int. 2008;28(2):160-74.

33. Xu J, Zhu X, Wu L, Yang R, Yang Z, Wang Q, Wu F. MicroRNA-122 suppresses cell proliferation and induces cell apoptosis in hepatocellular carcinoma by directly targeting Wnt/ $\beta$ catenin pathway. Liver Int. 2012;32:752-60.
34. Li C, Wang Y, Wang S, Wu B, Hao J, Fan H, Ju Y, Ding Y, Chen L, Chu X, Liu W, Ye X, Meng S. Hepatitis B virus mRNAmediated miR-122 inhibition upregulates PTTG1-binding protein, which promotes hepatocellular carcinoma tumor growth and cell invasion. J Virol. 2013;87:2193-205.

35. Li ZY, Xi Y, Zhu WN, Zeng C, Zhang ZQ, Guo ZC, Hao DL, Liu G, Feng L, Chen HZ, Chen F, Lv X, Liu DP, Liang CC. Positive regulation of hepatic miR-122 expression by HNF4 $\alpha$. J Hepatol. 2011;55:602-11.

36. Laudadio I, Manfroid I, Achouri Y, Schmidt D, Wilson MD, Cordi S, Thorrez L, Knoops L, Jacquemin P, Schuit F, Pierreux CE, Odom DT, Peers B, Lemaigre FP. A feedback loop between the liver-enriched transcription factor network and miR-122 controls hepatocyte differentiation. Gastroenterology. 2012;142:119-29.

37. Song K, Han C, Zhang J, Lu D, Dash S, Feitelson M, Lim K, Wu T. Epigenetic regulation of MicroRNA-122 by peroxisome proliferator activated receptor-gamma and hepatitis $\mathrm{b}$ virus $\mathrm{X}$ protein in hepatocellular carcinoma cells. Hepatology. 2013. doi: 10. 1002/hep.26514. (Epub ahead of print).

38. Wang B, Hsu SH, Wang X, Kutay H, Bid HK, Yu J, Ganju R, Jacob S, Yuneva M, Ghoshal K. Reciprocal regulation of miR122 and c-Myc in hepatocellular cancer: Role of E2F1 and TFDP2. Hepatology. 2013. doi: 10.1002/hep.26712. (Epub ahead of print).

39. Lin CJ, Gong HY, Tseng HC, Wang WL, Wu JL. miR-122 targets an anti-apoptotic gene, Bcl-w, in human hepatocellular carcinoma cell lines. Biochem Biophys Res Commun. 2008;375:315-20.

40. Wu X, Wu S, Tong L, Luan T, Lin L, Lu S, Zhao W, Ma Q, Liu $\mathrm{H}$, Zhong Z. miR-122 affects the viability and apoptosis of hepatocellular carcinoma cells. Scand J Gastroenterol. 2009;44:1332-9.

41. Ma L, Liu J, Shen J, Liu L, Wu J, Li W, Luo J, Chen Q, Qian C. Expression of miR-122 mediated by adenoviral vector induces apoptosis and cell cycle arrest of cancer cells. Cancer Biol Ther. 2010;9:554-61.

42. Hsu SH, Yu B, Wang X, Lu Y, Schmidt CR, Lee RJ, Lee LJ, Jacob ST, Ghoshal K. Cationic lipid nanoparticles for therapeutic delivery of siRNA and miRNA to murine liver tumor. Nanomedicine. 2013;9:1169-80.

43. Xu Y, Xia F, Ma L, Shan J, Shen J, Yang Z, Liu J, Cui Y, Bian X, Bie P, Qian C. MicroRNA-122 sensitizes HCC cancer cells to adriamycin and vincristine through modulating expression of MDR and inducing cell cycle arrest. Cancer Lett. 2011;310:160-9.

44. Yang F, Zhang L, Wang F, Wang Y, Huo XS, Yin YX, Wang YQ, Zhang L, Sun SH. Modulation of the unfolded protein response is the core of microRNA-122-involved sensitivity to chemotherapy in hepatocellular carcinoma. Neoplasia. 2011;13:590-600. 